\title{
PUBLICATIONS
}

\section{The Evanston Colloquium Lectures on Mathematics}

Delivered from August 28 to September 9, 1893, Before Members of the Congress of Mathematios Held in Connection with the World's Fair in Chicago, at Northwestern University, Evanston, Ill.

\section{By FELIX KLEIN}

REPORTED BY ALEXANDER ZIWET

Republished by the Society, 1911. Price 75 cents. Orders should be addressed to the Society. 